\section{Forma e função no desenvolvimento fonológico: quando uma palavra é uma palavra}

Form and function in phonological development: when a word is a word

Maria de Fátima de Almeida BAIA (UESB)
mariadefatimabaia@uesb.edu.br
Jéssica Caroline Souza AGUIAR (UESB)
aguiar.jcs.@gmail.com

Recebido em: 30 de out. de 2019. Aceito em: 17 de fev. de 2020.
BAIA, Maria de Fátima de Almeida; AGUIAR, Jéssica Caroline Souza.

Forma e função no desenvolvimento fonológico: quando uma palavra é uma palavra. Entrepalavras, Fortaleza, V. 10, n. 1, p. 166-189, jan-abr/2020. DOI: $10.22168 / 2237-6321-11750$.

Resumo: Neste estudo, com o intuito de discutir o pareamento de forma e função no desenvolvimento linguístico inicial, apresentamos o método proposto por Vihman e McCune (1994) para a categorização das produções iniciais do bebê na transição entre balbucio e palavras. Antes de apresentar o método, discutimos os modelos emergentistas/ funcionalistas que norteiam o método proposto pelos autores, a saber, o modelo biológico de Locke (1993), o modelo de auto-organização de Kent (1984) e o modelo funcionalista de Bates e MacWhinney (1989). Após apresentar o método, por meio da análise de dados de transição de sete crianças, três da cidade de São Paulo e quatro da cidade baiana de Vitória da Conquista, exemplificamos os passos para categorização dos dados e observamos que o pareamento de forma e função ocorre após 1 ano e 7 meses. Por fim, discutimos a variabilidade inter $\mathrm{e}$ intradialetos no que se refere ao pareamento de forma e função no desenvolvimento linguístico inicial.

Palavras-chave: fonológico. Funcionalismo.
Desenvolvimento Emergentismo. 
Abstract: In this study, in order to discuss the pairing of form and function in early language development, we present the method proposed by Vihman and McCune (1994) for the categorization of baby's initial productions in the transition between babbling and words. Before presenting the method, we discuss the emergentist / functionalist models that guide the method proposed by the authors, namely Locke's biological model (1993), Kent's self-organization model (1984) and Bates and MacWhinney (1989)'s Functionalist model. After presenting the method, through the analysis of transition data from seven children, three from the city of São Paulo and four from the city of Vitória da Conquista in Bahia, we exemplify the steps for data categorization and we observe that the pairing of form and function starts at one year and seven months. Finally, we discuss inter and intradialect variability regarding the pairing of form and function in early language development.

Abstract: Phonological development. Emergentism. Functionalism.

\section{Introdução}

Um dos desafios para o pesquisador de desenvolvimento fonológico inicial é lidar com a transição entre o período do balbucio e a entrada no estágio das primeiras palavras, isto é, quando temos o encontro da forma com a função linguística. Neste estudo, exploramos tal desafio por meio da relação entre forma fonológica e significado nas produções iniciais da criança por meio do uso do método proposto por Vihman e McCune (1994) e análise de dados iniciais de desenvolvimento. Ademais, o intuito é apresentar, inicialmente, um panorama a respeito da relação forma e função nos dados iniciais de criança com base em diferentes perspectivas.

Dessa forma, abordamos a transição no desenvolvimento, focando o papel da forma e da função na constituição do que consideramos primeiras palavras, trazendo para a discussão diferentes abordagens que podem ser consideradas funcionalistas e/ou emergentistas: a) Sistemas Adaptativos Complexos com os modelos de auto-organização (KENT, 1984; LINDBLOM, 1992; THELEN; SMITH, 1994); b) Modelos biológicos (LOCKE, 1993); c) Abordagem funcionalista (BATES; MACWHINNEY, 1989; BUDWIG, 1995).

Por fim, apresentamos, por meio da análise de dados de transição entre balbucio e primeiras palavras de sete crianças, o método de Vihman e McCune (1994) para tabulação de candidatos que podem ser considerados palavras na zona de transição, isto é, candidatos que apresentam organização fonológica e sentido. 
V. $10(1)$ 166-189 jan-abr 2020

\section{Diferentes abordagens sobre o desenvolvimento linguístico inicial}

Como Clark (2003, p. 103) aponta, pesquisadores de fala infantil têm ignorado o balbucio mesmo quando ele ocorre em sessões juntamente com produções identificadas como palavras. Assim como Clark (2003) observa em seu estudo, os dados que são analisados neste trabalho ilustram "several months of overlap" entre produções de palavras e de balbucio, o que é decerto verificado graças ao uso de dados naturalísticos e longitudinais. Podemos entender porque pesquisadores têm ignorado o balbucio e aspectos da transição, pois a área de desenvolvimento da linguagem carece de métodos que facilitam a identificação do que poderia ser considerado palavra ou não.

Há pesquisadores, como Albano (1999, p. 141), que destacam que enunciados aparentemente balbuciados podem ser, na verdade, componentes fônicos de uma palavra ou expressão que faz sentido, mas não é produzido inteligivelmente ainda. Contudo, por mais que seja aparentemente difícil de detectar e diferenciar balbucio de palavra na análise de dados iniciais devido às produções semelhantes e parcialmente simultâneas, a tarefa pode ser menos árdua e mais confiável se critérios forem estabelecidos, como é feito no método a ser abordado neste estudo. No que diz respeito à nossa concepção de palavra nos dados iniciais, ela ficará clara a partir da exposição do método que apresentamos ${ }^{2}$.

A seguir elencamos alguns modelos sobre o desenvolvimento linguístico inicial com foco nos emergentistas e funcionalistas, os quais norteiam o método proposto por Vihman e McCune (1994) a ser apresentado neste estudo.

Abordagens emergentistas/funcionalistas

Dentro do escopo das abordagens emergentistas ou funcionalistas, como Vihman (1996) as organiza, temos diferentes visões representadas em modelos, que apesar de não atribuírem o caráter de inato ao que poderia ser conhecimento prévio de língua, apresentam diferentes explicações acerca de como seria a organização linguística inicial no contato com o ambiente.

\footnotetext{
1 "Vários meses de sobreposição" (tradução nossa), isto é, balbucio sendo produzido tardiamente em período no qual já existem produções de palavras.

2 Para uma discussão aprofundada a respeito das palavras iniciais no desenvolvimento linguístico, ler Gerken (2008).
} 
A primeira abordagem a ser discutida é a biológica, a qual tem como intuito principal buscar as origens fonológicas no surgimento das capacidades perceptuais e motoras da espécie (VIHMAN, 1996). Dentre os estudiosos que propõem tal modelo, está Locke (1993), que assim como os demais (LINDBLOM, 1992), defende um interesse que ultrapassa os modelos emergentistas apenas baseados nos dados e na análise indutiva, ao derivar unidades e processos fonológicos de maneira dedutiva. Além disso, Locke (1993) foi o primeiro teórico do modelo a articular uma abordagem biológica para o desenvolvimento fonológico. Nesse estudo, ele apresenta três estágios que descrevem o desenvolvimento fonológico inicial do bebê segundo o modelo biológico: 1) estágio pragmático - nele, o bebê começa a reconhecer as consequências auditivas dos seus próprios gestos fonéticos; haveria, então, o início da função fonológica para a criança por meio da intenção de se comunicar vocalmente; 2) estágio cognitivo - inicia a partir do momento em que a criança começa a mostrar as primeiras tentativas de produzir a palavra do adulto, mesmo que ainda que estejam próximas das vocalizações do estágio anterior; tudo isso é possível, segundo o autor, por meio de um trabalho conjunto com outras operações cognitivas, tais como atenção, estocagem, recuperação (memória), e padrões de combinação; 3) estágio sistêmico - marcado por mudanças não em nível de sentido (função), mas no formato fônico do léxico. Dessa maneira, na sua proposta, Locke defende que forma e função vão sendo aprimoradas de maneira não simultânea no início do desenvolvimento.

Ademais, no mesmo estudo, Locke propõe uma interpretação neurológica para o desenvolvimento linguístico inicial do bebê, a qual ele caracteriza como sociobiológica. Para o autor, essa transição entre o que apresenta função nos dados linguísticos para o que já apresenta forma ocorre por meio de uma mudança do comportamento prélinguístico para o linguístico. Segundo o autor, haveria dois sistemas no ser humano relevantes para a linguagem: a) especialização na cognição social - estaria presente desde o nascimento e seria responsável pela busca da criança por faces e vozes, além do foco dado à prosódia e à fala dirigida a ela; é por causa dela que é possível observar a criança tentando acomodar a sua voz aos padrões do input, dando sequência, assim, com produção de palavras e sentenças; b) módulo linguístico - nele estariam o sistema interno que não é compartilhado com outra espécie, composto especificamente por fonologia e morfossintaxe (LOCKE, 1993, p. 35). 
V. $10(1)$ 166-189 jan-abr 2020

O autor não chega a mencionar os pressupostos de uma análise inatista gerativista com a proposta de gramática universal (CHOMSKY, 1981) para sabermos se se aproximaria da ideia de faculdade da linguagem. Todavia, ao afirmar que:

Crianças não vêm pré-estabelecidas para aprender língua. Em vez disso, elas estudam o movimento das faces e das vozes - o que é observável a partir dos falantes - e gradualmente se acomodam e reproduzem esses comportamentos. (LOCKE, 1993, p. 18) 3

Para Locke, o módulo linguístico presente na espécie não seria dado por natureza, mas emergiria de acordo com a interação com o ambiente.

O interessante da proposta de Locke (1993) está no fato de levar em consideração aspectos cognitivos que estão em desenvolvimento paralelamente com a linguagem, por exemplo, a atenção guiada em desenvolvimento faz com que o bebê preste atenção em padrões sonoros, ritmos e vozes familiares desde o útero (JUSCZYK; BERTONCINI, 1988); após a saída do útero da mãe, essa atenção é guiada para as faces dos cuidadores e é responsável pela rapidez com a qual se desenvolve a familiaridade com outras experiências sensoriais.

A segunda abordagem emergentista a ser discutida é a dos modelos de auto-organização. Trata-se de uma abordagem complementar da abordagem biológica. O diferencial é que sua ênfase está nos precursores do controle motor da fala por meio da noção de "auto-organização", princípio fundamental nos estudos de Sistemas Dinâmicos (THELEN, 1981; KENT, 1984; LINDBLOM, 1992).

Nessa perspectiva dinâmica, o desenvolvimento articulatório inicial da criança ocorre de maneira não linear e contínua como o de qualquer sistema dinâmico em desenvolvimento:

A aquisição do controle motor da fala é um processo contínuo e não linear. Períodos "sensíveis" de não linearidade ocorrem quando mudanças neurais, musculoesqueléticas, ambientais e cognitivas combinam (ou se juntam) no organismo individual. Os pontos no tempo de cada um desses fatores combinados podem resultar em "pulos de desempenho" [períodos de "descoberta" e reorganização]. (KENT, 1984, p. 136)4

3 "Infants do not really set out to learn languages. Instead, they study the movement of faces and voices - the observable displays of talkers - and gradually accommodate to and reproduce these behaviors" (LOCKE, 1993, p. 18, tradução nossa).

4 "The acquisition of speech motor control is a continuous but non-linear process. "Sensitive" periods of nonlinearity occur when certain neural, musculoskeletal, environmental, and cognitive changes combine (or "get together") in the individual organism. The points in time 
Kent (1984) apresenta os seguintes princípios que explicam o carácter auto-organizatório do desenvolvimento linguístico inicial em cooperação com outros sistemas que se organizam no indivíduo: 1) a anatomia do trato vocal muda significativamente no primeiro ano de vida, o que tem um efeito direto no inventário de sons que o bebê pode produzir; isso ocorre devido à maturação que envolve uma ascenção progressiva do sistema nervoso central e o controle cortical que é alcançado na metade do primeiro ano de vida; 2) a ritmicidade é uma base natural dos sistemas de movimento; o autor, de acordo com Thelen (1981), pontua que a sua importância para o controle motor da fala pode ser sugerida pelo fato de que as primeiras sílabas produzidas pela criança surgem junto com o desenvolvimento motor geral; 3) produção e percepção têm origens separadas no desenvolvimento da criança e devem se integrar ao longo dos primeiros meses de vida de acordo com a exposição à língua ambiente; 4) a primeira unidade de contraste da criança na produção de fala deve ser a palavra, isto é, a criança deve relacionar a palavra que pretende produzir com um plano motor ou pauta gestual.

Assim como Kent, Lindblom (1992), que segue o mesmo modelo de auto-organização, defende que a complexidade do sistema linguístico não pode ser compreendida apenas como produto de programação genética ou processos ambientais. Segundo o autor, é por meio da interação dos dois que o sistema linguístico pode emergir.

Por último, o terceiro modelo também emergentista, que orienta o método a ser apresentado neste estudo, é o funcionalista. Nele, Bates e MacWhinney (1989) chamam a atenção para o fato de que há diferenças potenciais entre o pareamento forma e função da criança e do adulto. Por essa razão, qualquer método que queira oferecer ferramentas para mapear o que seria ou não palavra no desenvolvimento inicial deve conhecer de maneira aprofundada a gramática específica da criança. Uma outra necessidade, pontuada por Budwig (1995), é a de que qualquer abordagem funcionalista de desenvolvimento linguístico deve considerar que a língua é adquirida de acordo com as funções comunicativas, isto é, deve reconhecer que a língua é organizada de acordo com as necessidades daqueles que a usam. A autora continua afirmando que:

at which a particular number of these factors combine can result in "jumps" in performance" [periods of "discovery" and reorganization]" (KENT, 1984, p. 136, tradução nossa). 
V. $10(1)$

166-189

jan-abr

2020

[...] a crença de que a língua é um sistema de formas e significados. Formas são veículos através dos quais os significados podem ser realizados. Dessa maneira, em uma pesquisa de orientação funcionalista, as formas são vistas como um meio para um fim, e não apenas o fim. (BUDWIG, 1995, p. 4)

Dessa maneira, no desenvolvimento linguístico inicial, a função guia a forma, isto é, a partir do momento em que a criança tem um conjunto de funções, ela busca formas para parear com as funções. Todavia, ressaltamos que nem todos funcionalistas vão defender que a função guia a forma no desenvolvimento linguístico, por exemplo, Bates e MacWhinney (1989), em um modelo funcionalista intitulado modelo de competição, defendem que a relação entre forma e função deve ser entendida em termos de correlações horizontais e verticais.

Por fim, uma outra proposta funcionalista é a de Halliday (2003, p. 215), que explica que por volta de cinco a seis meses, a criança é capaz de construir e utilizar um símbolo para se referir a algo. Embora esse fenômeno não seja muito explorado, o autor aponta que este ato é importante, pois é o primeiro signo (uma expressão pareada com um significado) utilizado pela criança, sendo ele um primeiro passo crítico para a entrada da criança em um sistema semiótico. Por volta dos sete a dez meses, a partir dos signos criados, o bebê constrói o seu primeiro sistema semiótico, chamado por Halliday (2003, p. 216) de protolíngua. De acordo com o autor, há algumas pré-condições para que haja uma protolíngua:

(i) que a criança possa agora controlar uma variedade de movimentos gestuais e vocais, isto é, ela tem o potencial para criar expressões; (ii) que ela tenha identificado uma gama de contextos interpessoais para atos de sentido, nos quais as expressões serão reconhecidas e decodificadas, isto é, ela tem o potencial para criar conteúdo; (iii) ela tenha aprendido a parear conteúdo e expressão em um único signo complexo; e (iv) ela é reconhecida pelos outros como um interlocutor, como sendo uma pessoa e, consequentemente, alguém que significa. (HALLIDAY, 2003, p. 216) ${ }^{6}$

\footnotetext{
5 "[...] the belief that language is a system of forms and meanings. Forms are a vehicle through which the meanings can be realized. Thus, in functionally oriented research, forms are viewed as a means to an end rather than as an end" (BUDWIG, 1995, p. 4, tradução nossa).

${ }^{6}$ (i) "that the child can now control a range of vocal and gestural movements, that is, he has the potential for creating expressions; (ii) that he has identified a range of interpersonal contexts for acts of meaning, in which the expressions will be recognized and decoded, that is, he has the potential for creating contents; (iii) he has learnt to pair content and expression in a single complex sign; and (iv) he is recognized by the others as a communicator, as being a person and hence someone who means" (HALLIDAY, 2003, p. 216, tradução nossa).
} 
Embora esses pré-requisitos se assemelhem às habilidades necessárias para que a criança desenvolva o sistema linguístico, visto que eles envolvem questões de percepção/produção do signo e de compreensão/significação do mesmo, eles ainda não são o suficiente para que haja uma língua, pois, conforme Halliday (2003, p. 219), eles abarcam apenas dois níveis, o do conteúdo e o da expressão, enquanto que, no sistema linguístico, existem três níveis: o da forma, o da função e o da gramática, sendo este último um nível puramente abstrato.

Mas, então, quando e como ocorre a transição da protolíngua para o sistema linguístico? Em relação ao período da transição, Halliday (2003, p. 221) afirma que esse ocorre na segunda metade do segundo ano de vida, entre $1 ; 6$ a 2;0 anos de idade. Vihman (2014, p. 35), no entanto, aponta que essa transição ocorre entre o período de 1;0 a 1;6 de idade. Quanto ao modo como ocorre essa passagem, Halliday (2003, p. 222) propõe que uma estratégia geral utilizada pela criança durante esse período é o uso das funções pragmática (imperativa) e matética (declarativa), sendo que essa distinção entre as duas funções não é feita apenas pela forma da expressão, mas também pelo feedback dado pelo interlocutor em relação à produção. Segundo o autor, cada expressão produzida pela criança nesse período é restrita a um dos dois tipos de função, não podendo, em um momento, por exemplo, dizer uma expressão com a função pragmática e, em outro, falar a mesma expressão com a função matética. Em um nível mais avançado da transição, Halliday (2003, p. 223) afirma que as funções se tornam o princípio organizacional principal da gramática, podendo ser qualquer sentença utilizada como uma ação ou como uma representação, a depender da intenção comunicativa da criança. A unidade da gramática passa a ser então a oração.

Dessa maneira, Halliday (2003), diferentemente dos outros estudos emergentistas/funcionalistas apresentados até então, defende que a unidade linguística inicial da criança não seria a palavra, mas a sentença pensando nos primeiros enunciados como holófrases. Entretanto, não é essa visão que é defendida por Vihman e McCune (1994) no seu método de identificar enunciados iniciais com pareamento entre forma e função.

A seguir, apresentamos a abordagem centrada na palavra. 
V. 10 (1) 166-189 jan-abr 2020

\section{A palavra como unidade fônica inicial}

Não é possível falar de desenvolvimento fonológico sem considerar o surgimento do que se considera palavra. Gerken (2008) chama a atenção para o que se considera protopalavra e que não pode ser confundido com palavra inicial. Protopalavra, segundo a autora, é a produção que se distancia do alvo, geralmente composta por uma ou duas sílabas, e é usada em determinados contextos pela criança para chamar a atenção do adulto, como, por exemplo, [di], usado para se referir a um objeto qualquer (GERKEN, 2008, p. 73).

O que Gerken (2008) considera protopalavra pode ser considerado palavra inicial na perspectiva da Whole-Word (Templatic) Phonologyse houver evidência de que tais produções distorcidas são fruto da manifestação de um template ${ }^{7}$ predominante. Dessa maneira, no presente estudo, a classificação entre protopalavra e palavra inicial não é levada em consideração.

A visão assumida pela presente pesquisa e no método a ser apresentado é a de que o desenvolvimento fonológico começa partindo da palavra como unidade fonológica mínima. Essa perspectiva nomeada Whole-Word Phonology é uma abordagem particular sobre o desenvolvimento fonológico, a qual tem ganhado apoio gradualmente desde a década de 70 (FERGUSON; FARWELL, 1975; MACKEN, 1979; INGRAM; INGRAM, 2001; VIHMAN; VELLEMAN, 2002; VIHMAN; CROFT, 2007; FIKKERT; LEVELT, 20088). Dessa maneira, a hipótese de que a palavra é a unidade fônica inicial do desenvolvimento tem sido assumida por estudos de base inatista, emergentista/dinâmica e funcionalista.

A Whole-Word Phonology teve sua primeira elaboração no estudo de Waterson (1971). A autora apresenta vantagens do modelo após observar o uso de formas que não apresentavam relação com o alvo, mas que podiam entendidas como determinada palavra por causa do uso em um contexto específico. A autora observa que uma das crianças produziu palavras com palatal nasal inicial, embora tal fonema não ocorra no inglês adulto, exceto quando se trata da produção do encontro consonantal [nj] (VIHMAN; VELLEMAN, 2002):

\footnotetext{
7 Template pode ser entendido como um padrão fônico que pode carregar tanto informação prosódica e/ou segmental no seu formato. Esse padrão serve como ferramenta para a expansão lexical (VIHMAN, 1996). Não traduzimos o termo em português por se tratar de um termo específico do modelo (cf. BAIA, 2014).

8 O estudo de Fikkert e Levelt (2008) é o único dos citados que parte de uma abordagem simbólica/inatista para explicar o desenvolvimento fonológico. A proposta das autoras parte da combinatória de segmentos de acordo com o ponto de articulação para explicar o desenvolvimento fonológico. Não é, portanto, uma abordagem estritamente holística, mas sim uma proposta que enfatiza a relação entre léxico e fonologia.
} 
Produção infantil

(1) ['nẽ.nẽ]/ ['ni.ni]

(2) ['nẽ.nẽ]

(3) [' 'nã.nã]

(4) [' 'nã.nø]
Alvo

finger

window

another

Randall

\section{Glosa}

dedo

janela

outro

nome de cabra

(WATERSON, 1971, p. 179)

A permanência do padrão com a nasal é temporária, pois ele tende a entrar em desuso a partir do momento em que outro é incorporado ou quando aspectos articulatórios do alvo já foram adquiridos e estabilizados ${ }^{9}$.

Falta, nesse primeiro momento da perspectiva, precisão sobre como classificar e identificar o que seria (ou não) uma palavra com distorção. Além disso, faltam hipóteses acerca da origem das rotinas, papel da faixa etária, tipologia de língua, etc. No entanto, esses não eram os objetivos de Waterson (1971) que, no seu estudo, descreve a fonologia inicial de uma criança apresentando a variabilidade fônica nos dados iniciais.

O método que apresentamos na próxima seção foi proposto como meio de classificar, no meio de tais rotinas, o que seria um bom candidato à palavra.

\section{Método de Vihman e McCune (1994)}

O método utilizado neste trabalho

Como foi discutido até então, o estudo de dados iniciais, que parte da classificação do que pode ou não ser avaliado como palavra, exige categorização devido às tênues diferenças entre o que é palavra ou não no período inicial da fala. Por certo, o contexto, semelhança fônica e a repetição da palavra com o uso constante de um mesmo sentido são fundamentais para a categorização, mas não são os únicos critérios considerados para a classificação dos dados iniciais (balbucio e palavra).

Vihman e McCune (1994), baseados na análise de dados de transição do balbucio às primeiras palavras de dez crianças entre nove meses e um ano e seis meses de idade, propõem critérios que partem de parâmetros contextuais e fônicos para determinarem quando a palavra pode ser entendida como palavra fonológica. Sobre a necessidade de haver

9 Para uma discussão aprofundada a respeito das adaptações iniciais, ler Vihman (1996). 
V. 10 (1) 166-189 jan-abr 2020 tais critérios, os autores lembram que tal preocupação de reconhecer o que seria "primeira palavra" tem acompanhado especialistas em fala infantil antes do advento da pesquisa psicolinguística contemporânea.

Vihman e McCune (1994) propõem, então, uma nova metodologia para identificação de palavra sem apresentar novos termos ou conceitos. Em vez de novas terminologias, os autores sugerem o uso de critérios fonológicos que levem em consideração o contexto de interação também.

Os critérios são aplicados antes na seleção prévia das produções que levantam dúvidas. O candidato à palavra que suscita dúvidas quanto à sua categorização deve apresentar aspectos fônicos próximos ao do alvo e/ou pistas de contexto específico de uso para não ser descartado de início. Após a identificação daqueles que suscitam dúvidas, os seguintes grupos de critérios são seguidos:

a) Critérios baseados no contexto: determinativo - verificase se a palavra ocorre em um contexto sugestivo de uma determinada palavra e não de outra; identificação materna - verifica-se por meio do estudo da interação adulto e criança, ou seja, se o adulto entende o candidato à palavra da mesma maneira que o pesquisador; uso múltiplo - verificase se a criança utiliza a mesma produção mais de uma vez no mesmo episódio; episódios múltiplos - verifica-se se a criança utiliza a mesma produção em diferentes episódios.

b) Critérios baseados no modelo de vocalização: correspondência complexa - verifica-se se a produção da criança contém mais de dois segmentos da forma alvo; correspondência segmental exata - verifica-se se até um ouvido não treinado reconheceria a produção da criança como sendo idêntica à produção-alvo; correspondência prosódica - verifica-se se as características prosódicas são as mesmas presentes na forma alvo, i.e., posição de acento, tipo e quantidade silábica.

c) Critérios baseados em outras vocalizações: tokens imitados - verifica-se se o candidato à palavra é uma produção imitada e se a criança compreende o que imita; ausência de variação - verifica-se se o candidato à palavra é repetido mais de uma vez sem variação fonética; ausência de usos inapropriados - verifica-se se a produção mantém o mesmo significado em diferentes contextos. 
A correspondência fonética, segundo os autores, não é cópia idêntica dos segmentos do alvo ${ }^{10}$. Vogais que ocupam lugares vizinhos no quadro do IPA, por exemplo [a] sendo produzido como [ə] em "casa", não são tratadas como diferentes seguindo os critérios propostos. $\mathrm{O}$ critério de correspondência também é obedecido quando consoantes são produzidas com aspiração quando o alvo não o é, e sibilantes produzidas com troca de ponto de articulação.

Vihman e McCune (1994) propõem que um bom candidato será aquele que respeitar no mínimo quatro critérios. O presente estudo faz uso de todos os critérios listados nos grupos a, b e c, como também assume o número mínimo proposto pelos autores na análise dos dados. Em outras palavras, na dúvida se o candidato a palavra pode realmente ser considerado palavra, as produções que não satisfizerem pelo menos quatro critérios serão categorizadas como balbucio.

\section{Dados analisados}

Neste estudo, com uso do método de Vihman e McCune (1994), analisamos dados de três crianças de São Paulo (M., A., G.) do banco de dados da Universidade de São Paulo (SANTOS, 2005) e de quatro crianças (L., D., M., B.) do banco de dados do GEPDEF (Grupo de Estudos de Psicolinguística e Desenvolvimento Fonológico) da Universidade Estadual do Sudoeste da Bahia (BAIA, 2014) em Vitória da Conquista (BA). São analisadas sessões mensais das sete crianças no intervalo de 1 a 2 anos. Os dados são longitudinais e naturalísticos, coletados na residência das crianças (em São Paulo) e no Laboratório de Aquisição da Linguagem e Aspectos Linguísticos (LALALIN) da UESB (em Vitória da Conquista). Os dois corpora foram autorizados pelo comitê de ética das respectivas universidades: USP (cf. SANTOS, 2005) e UESB (CAAE 30366814.1.0000.0055).

\footnotetext{
${ }^{10}$ Embora façam uso da palavra "exata" em "Correspondência Segmental Exata" nos critérios do item b, Vihman e McCune (1994) explicam não haver necessidade de cópia idêntica para verificação da correspondência fonética. Conferir definição do critério.
} 
V. 10 (1) 166-189 jan-abr 2020

\section{Análise e Discussão dos dados}

Passos iniciais para análise de acordo com o método de Vihman e McCune (1994)

O método de Vihman e McCune (1994) sugere que inicialmente devem ser identificados os dados que geram dúvida quanto a serem ou não uma palavra. Para exemplificar como os critérios do método funcionam, apresentamos dois candidatos que não foram considerados palavra, nos dados de M. (SP), por não obedecerem ao mínimo de quatro critérios, e dois candidatos que foram classificados como palavra. Os exemplos apresentados ilustram como cada candidato suspeito foi verificado por meio dos critérios propostos por Vihman e McCune (1994). A formaalvo apresentada como glosa foi sugerida como candidato suspeito de acordo com o contexto de uso.

(1) Candidato negado ['go.go] - brinquedo (0;10.081ㅡㄴ $)$ abaixo está a transcrição do único momento no qual a criança produz o candidato na sessão analisada:

*CHI: gogo@c [=brinquedo]

\%pho: 'go.go

*MOT: $\quad$ cadê a vaquinha?

*MOT: dá a vaquinha p(a)ra mamãe@f, dá?12

Em relação aos critérios baseados no contexto, o candidato obedece ao critério determinativo por ocorrer em um contexto no qual o assunto é brinquedo, e ao critério de identificação materna por haver reconhecimento, por parte da mãe, de que a criança fala do brinquedo, mas não apresenta requisitos para satisfazer os critérios de uso múltiplo e episódios múltiplos por ocorrer apenas uma vez em uma única sessão. Os critérios baseados no modelo de vocalização não foram obedecidos por não haver nenhum tipo de correspondência fônica ou prosódica entre alvo e candidato. O mesmo pode ser dito sobre os critérios baseados em outras vocalizações, pois não houve imitação de alvo e repetição para verificar ausência de variação e de usos inapropriados.

\footnotetext{
${ }^{11}$ A leitura da notação de faixa etária é feita da seguinte maneira: o (ano); 10 (meses).08 (dias). 12 *CHI - child - criança, \%pho - phonetics - transcrição fonética, *MOT - mother - mãe. Para mais detalhes, ler MacWhinney (2000) e visitar o site CHILDES (Talkbanksystem): http://childes. psy.cmu.edu/.
} 
(2) Candidato negado [bi. 'a] - vassoura (1;16.13): a seguir está a transcrição dos momentos nos quais a criança produz o candidato na sessão analisada:

$\begin{array}{ll}\text { *MOT: } & \text { o que que é isso aqui? } \\ \text { *MOT: } & \text { ah@i? } \\ \text { *CHI: } & \text { a bia@c [=vassoura]. } \\ \text { \%pho: } & \text { a bi.'a } \\ \text { *MOT: } & \text { vassoura. } \\ \text { *MOT: } & \text { quem é esse aqui? } \\ \text { *CHI: } & \text { a bia@c [=abelha]. } \\ \text { \%pho: } & \text { a bi.'a } \\ \text { *MOT: } & \text { é abelha? } \\ \text { *MOT: } & \text { fala abelha. } \\ \text { *MOT: } & \text { quem é essa? } \\ \text { *CHI: } & \text { a bia@c [=abelha]. } \\ \text { \%pho: } & \text { a bi.'a }\end{array}$

Em relação aos critérios baseados no contexto, o candidato obedece ao critério determinativo por ocorrer em um contexto no qual o assunto é vassoura, ao critério de identificação materna por haver reconhecimento, por parte da mãe, de que a criança fala da vassoura, mas não apresenta requisitos para satisfazer os critérios de uso múltiplo e episódios múltiplos por ocorrer apenas uma vez em uma única sessão com o sentido aparente de "vassoura". A produção aparece outras vezes com o sentido de "abelha". Os critérios baseados no modelo de vocalização não foram obedecidos por não haver nenhum tipo de correspondência fônica ou prosódica entre alvo e candidato. O mesmo pode ser dito sobre os critérios baseados em outras vocalizações, pois não houve imitação de alvo e repetição para verificar ausência de variação e de usos inapropriados.

(3) Candidato aceito [ba. 'ba] - bola (1;01.14): a seguir está a transcrição do momento no qual a criança produz o candidato na sessão analisada:

*CHI:_aba@c[=bola],aba@c[=bola],aba@c[=bola].

\%pho: a ba a ba a ba

*AUN ${ }^{13}$ : a bola?

*AUN: $\quad$ vai lá pega(r)?

*CHI: a bo(la). 
V. $10(1)$

166-189

jan-abr

2020

\%pho: $\quad$ a bo

*CHI: baba@c [=bola].

\%pho: ba.'ba

Em relação aos critérios baseados no contexto, o candidato obedece ao critério determinativo por ocorrer em um contexto no qual o assunto é bola, ao critério de identificação materna por haver reconhecimento, por parte da tia, de que a criança fala de bola, e ao critério de episódios múltiplos por ocorrer em outra sessão com o mesmo sentido (2;00.14). O critério de uso múltiplo não foi obedecido por ter sido encontrada apenas uma produção na sessão. Em relação aos critérios baseados no modelo de vocalização, o critério de correspondência complexa foi obedecido por haver dois segmentos da forma-alvo na produção da criança, e o critério da correspondência prosódica, por haver características prosódicas compartilhadas pela produção e alvo (quantidade e tipo de sílaba). Não houve correspondência segmental exata entre o alvo e o candidato. Quanto aos critérios baseados em outras vocalizações, não houve imitação de alvo e repetição para verificar ausência de variação e de usos inapropriados.

(4) Candidato aceito [ta.'ta] - tchau (1;02.13): a seguir está a transcrição do momento no qual a criança produz o candidato na sessão analisada:

$\begin{array}{ll}\text { *AUN: } & \text { tchau. } \\ \text { *AUN: } & \text { dá tchau, dá. } \\ \text { *AUN: } & \text { tchau. } \\ \text { *CHI: } & \text { tatá@c [=tchau]. } \\ \text { \%pho: } & \text { ta.'ta } \\ \text { *AUN: } & \text { isso. } \\ \text { *AUN: } & \text { tchau. } \\ \text { *AUN: } & \text { (a)cabo }(u) .\end{array}$

Em relação aos critérios baseados no contexto, o candidato obedece ao critério determinativo por ocorrer em um contexto no qual o assunto é despedida (tchau), e ao critério de identificação materna por haver reconhecimento, por parte da tia, de que a criança fala tchau. Os critérios de uso múltiplo e episódios múltiplos não foram obedecidos por ocorrer apenas uma produção em uma única sessão. Em relação aos critérios baseados no modelo de vocalização, o critério 
de correspondência complexa foi obedecido por haver dois segmentos da forma-alvo na produção da criança. Não houve correspondência segmental exata e correspondência prosódica entre o alvo e o candidato. Quanto aos critérios baseados em outras vocalizações, o critério de tokens imitados foi obedecido, pois a produção foi resultado de tentativa de imitação do alvo. Como não houve repetição, os critérios ausência de variação e ausência de usos inapropriados não foram obedecidos.

A seguir, apresentamos um quadro com os candidatos a palavra de M. para ilustrar como foi feito o julgamento:

Quadro 1 - quadro para verificar os critérios de Vihman e McCune (1994)

\begin{tabular}{|c|c|c|c|c|c|c|c|c|c|c|c|c|}
\hline \multirow[b]{2}{*}{ 㞧 } & \multirow[t]{2}{*}{ ALVO } & \multicolumn{4}{|c|}{ CONTEXTO } & \multicolumn{3}{|c|}{$\begin{array}{l}\text { MODELO } \\
\text { VOCAL }\end{array}$} & \multicolumn{3}{|c|}{ OUTRO } & \multirow[t]{2}{*}{ DECISÃO } \\
\hline & & 葛 & 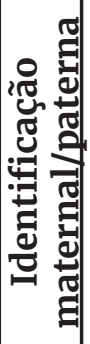 & 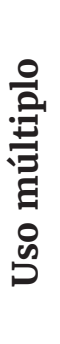 & 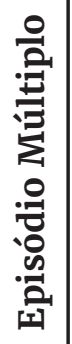 & ن & 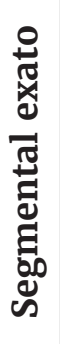 & 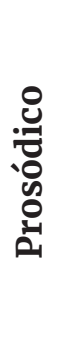 & 萢 & 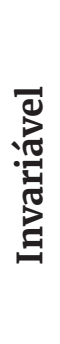 & 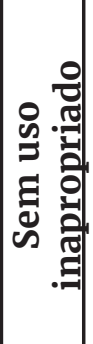 & \\
\hline [go.'go] & brinquedo & $\mathrm{X}$ & $\mathrm{X}$ & & & & & & & & & $\mathrm{NA} \mathrm{O}$ \\
\hline [ga.'ga] & bola/gol & $\mathrm{X}$ & $\mathrm{X}$ & $\mathrm{X}$ & & & & $\mathrm{X}$ & & $\mathrm{X}$ & $\mathrm{X}$ & SIM \\
\hline [pa.'pa] & Karine & $X$ & $\mathrm{X}$ & $\mathrm{X}$ & & & & $\mathrm{X}$ & $\mathrm{X}$ & $\mathrm{X}$ & & SIM \\
\hline ['ka.ka] & cocoricó & $\mathrm{X}$ & $\mathrm{X}$ & $\mathrm{X}$ & & & & $\mathrm{X}$ & $\mathrm{X}$ & $\mathrm{X}$ & & SIM \\
\hline [ba.'ba] & bola & X & $\mathrm{X}$ & X & & $X$ & & $X$ & & & & SIM \\
\hline [da.'da] & pé & $\mathrm{X}$ & $\mathrm{X}$ & X & & & & X & & $\mathrm{X}$ & X & SIM \\
\hline [e.'de] & cadermo & $\mathrm{X}$ & $\mathrm{X}$ & X & & $\mathrm{X}$ & & $X$ & & & $\mathrm{X}$ & SIM \\
\hline [ta.'ta] & tchau & $\mathrm{X}$ & $\mathrm{X}$ & & & $\mathrm{X}$ & & & $\mathrm{X}$ & & & SIM \\
\hline [gu.'ga] & pegar & $\mathrm{X}$ & $\mathrm{X}$ & & & $\mathrm{X}$ & & $X$ & & & X & SIM \\
\hline [ka.'ka] & caiu & $\mathrm{X}$ & $\mathrm{X}$ & & & $\mathrm{X}$ & & X & & & X & SIM \\
\hline [ji.'ji] & Eliane & $\mathrm{X}$ & $\mathrm{X}$ & $\mathrm{X}$ & & & & $\mathrm{X}$ & $\mathrm{X}$ & $\mathrm{X}$ & & SIM \\
\hline ['pu.ga] & $\begin{array}{l}\text { guarda- } \\
\text { chuva }\end{array}$ & $\mathrm{X}$ & $X$ & & & $\mathrm{X}$ & & $\mathrm{X}$ & $\mathrm{X}$ & & $X$ & SIM \\
\hline [bo.'bo] & cobra & $\mathrm{X}$ & $\mathrm{X}$ & & & $\mathrm{X}$ & & $X$ & $\mathrm{X}$ & & $\mathrm{X}$ & SIM \\
\hline [bi.'a] & vassoura & $\mathrm{X}$ & $\mathrm{X}$ & & & & & & & & & $\mathrm{NA} O$ \\
\hline ['bi.li] & bicho & $\mathrm{X}$ & $X$ & & & $\mathrm{X}$ & & $X$ & & & $X$ & SIM \\
\hline [bi.'gi.ga] & bexiga & $\mathrm{X}$ & $\mathrm{X}$ & $\mathrm{X}$ & $\mathrm{X}$ & $\mathrm{X}$ & & $\mathrm{X}$ & $\mathrm{X}$ & $\mathrm{X}$ & $\mathrm{X}$ & SIM \\
\hline [di.'de] & doente & $\mathrm{X}$ & $\mathrm{X}$ & & & $\mathrm{X}$ & & $\mathrm{X}$ & $\mathrm{X}$ & & & SIM \\
\hline [go.'go] & umbigo & $\mathrm{X}$ & $\mathrm{X}$ & $\mathrm{X}$ & & $\mathrm{X}$ & & $X$ & & & $\mathrm{X}$ & SIM \\
\hline [bi.'ti.tu] & vidro & $\mathrm{X}$ & $\mathrm{X}$ & & & $\mathrm{X}$ & & $\mathrm{X}$ & & & $\mathrm{X}$ & SIM \\
\hline [bi.'i.a] & estrela & $\mathrm{X}$ & $\mathrm{X}$ & & & $\mathrm{X}$ & & X & & & $\mathrm{X}$ & SIM \\
\hline
\end{tabular}


V. $10(1)$ 166-189 jan-abr 2020

Após a verificação dos candidatos suspeitos dos dados de cada criança, podemos tabular os dados da seguinte maneira:

Tabela $1^{14}$ - Total de produções de balbucio e de palavras seguindo o método de Vihman e McCune (1994)

\begin{tabular}{|c|c|c|}
\hline Criança & Faixa Etária & Total de produções \\
\hline 1. M. (SP) & $\begin{array}{l}09-2 ; 0 \\
16 \text { sessões/meses }\end{array}$ & $\begin{array}{l}\text { Balbucio: } 242 \text { produções } \\
\text { Palavras: } 1975 \text { tokens }\end{array}$ \\
\hline 2. A. (SP) & $\begin{array}{l}09-2 ; 0 \\
16 \text { sessões/meses }\end{array}$ & $\begin{array}{l}\text { Balbucio: } 382 \text { produções } \\
\text { Palavras: } 697 \text { tokens }\end{array}$ \\
\hline 3. G. (SP) & $\begin{array}{l}0 ; 10-2 ; 0 \\
15 \text { sessões/meses }\end{array}$ & $\begin{array}{l}\text { Balbucio: } 268 \text { produções } \\
\text { Palavras: } 939 \text { tokens }\end{array}$ \\
\hline 4. L. (BA) & $\begin{array}{l}1 ; 0-2 ; 0 \\
13 \text { sessões }\end{array}$ & $\begin{array}{l}\text { Balbucio: } 219 \text { produções } \\
\text { Palavras: } 1256 \text { tokens }\end{array}$ \\
\hline 5. D. (BA) & $\begin{array}{l}1 ; 5-2 ; 5 \\
13 \text { sessões }\end{array}$ & $\begin{array}{l}\text { Balbucio: } 492 \text { produções } \\
\text { Palavras: } 2200 \text { tokens }\end{array}$ \\
\hline 6. B. (BA) & $\begin{array}{l}1 ; 0-2 ; 0 \\
13 \text { sessões }\end{array}$ & $\begin{array}{l}\text { Balbucio: } 231 \text { produções } \\
\text { Palavras: } 1241 \text { tokens }\end{array}$ \\
\hline 7. M. (BA) & $\begin{array}{l}1 ; 0-2 ; 0 \\
13 \text { sessões }\end{array}$ & $\begin{array}{l}\text { Balbucio: } 165 \text { produções } \\
\text { Palavras: } 461 \text { tokens }\end{array}$ \\
\hline
\end{tabular}

Fonte: autoria própria.

Ao observarmos a distribuição de produções de balbucio e de palavras ao longo das sessões, notamos a simultaneidade dos dois tipos de produção até em sessões mais tardias. Os gráficos a seguir ilustram essa sobreposição nos dados de todas as crianças:

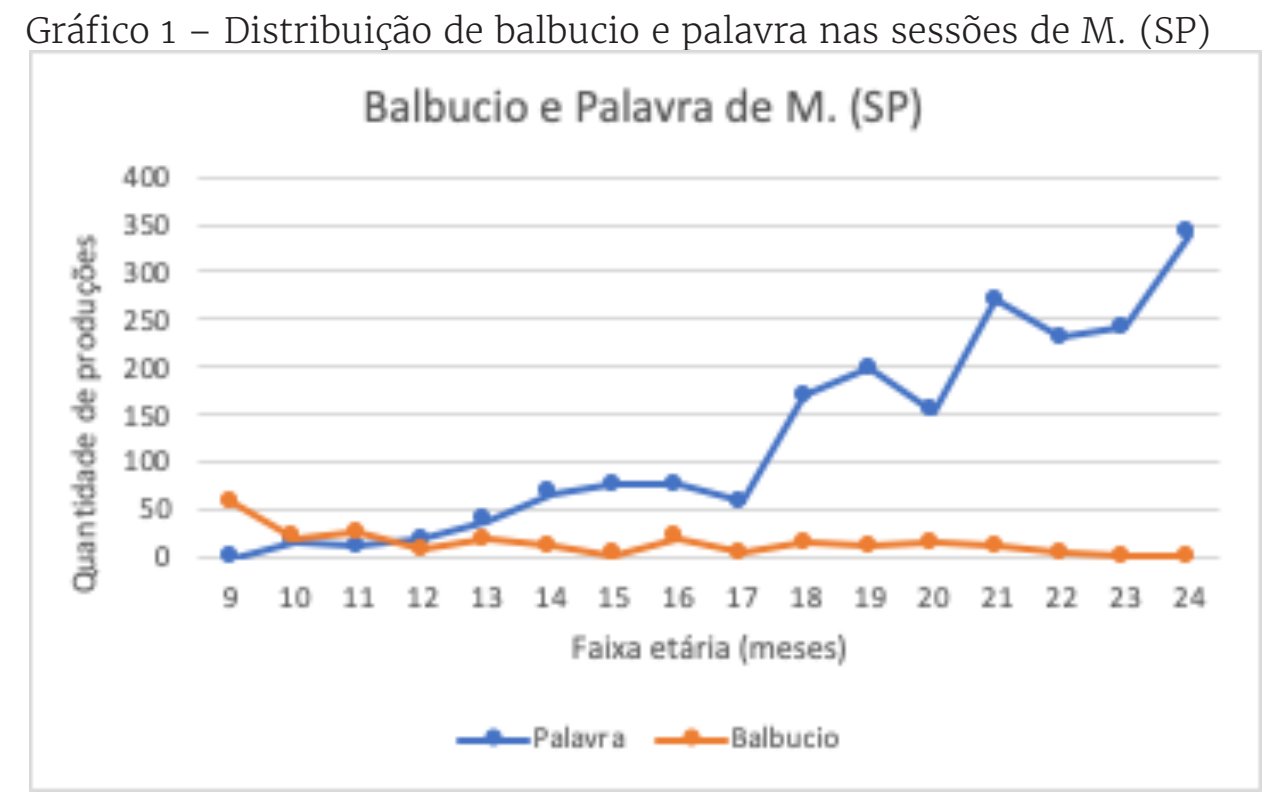

Fonte: autoria própria.

$\overline{14}$ Embora sejam analisados dados iniciais, o intervalo varia entre as crianças. Todavia, não acreditamos que essa diferença possa influenciar no resultado final. 
Gráfico 2 - Distribuição de balbucio e palavra nas sessões de A. (SP)

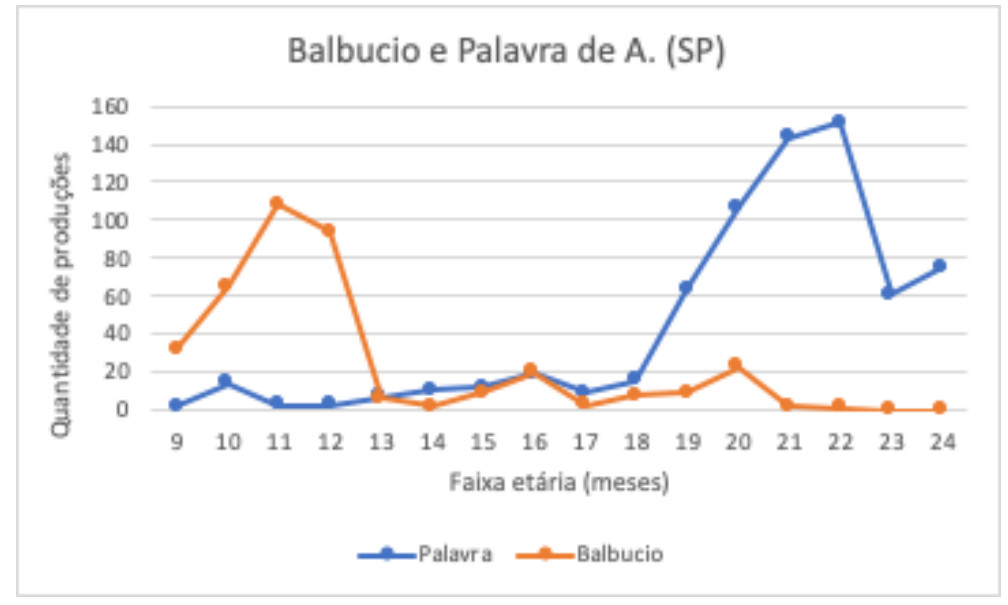

Fonte: autoria própria.

Gráfico 3 - Distribuição de balbucio e palavra nas sessões de G. (SP)

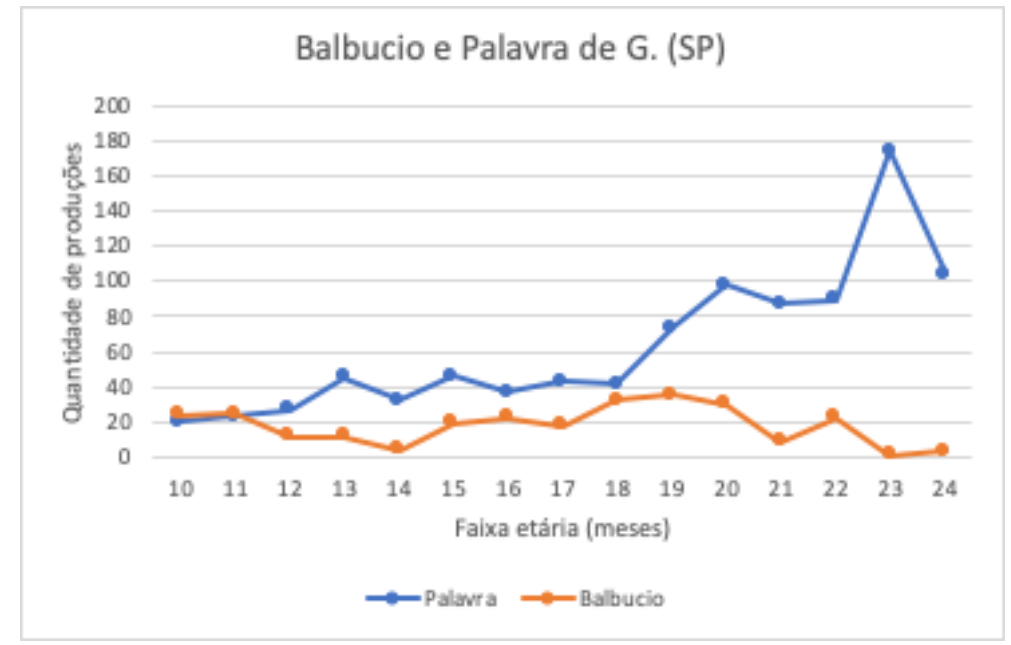

Fonte: autoria própria.

Gráfico 4 - Distribuição de balbucio e palavra nas sessões de L. (BA)

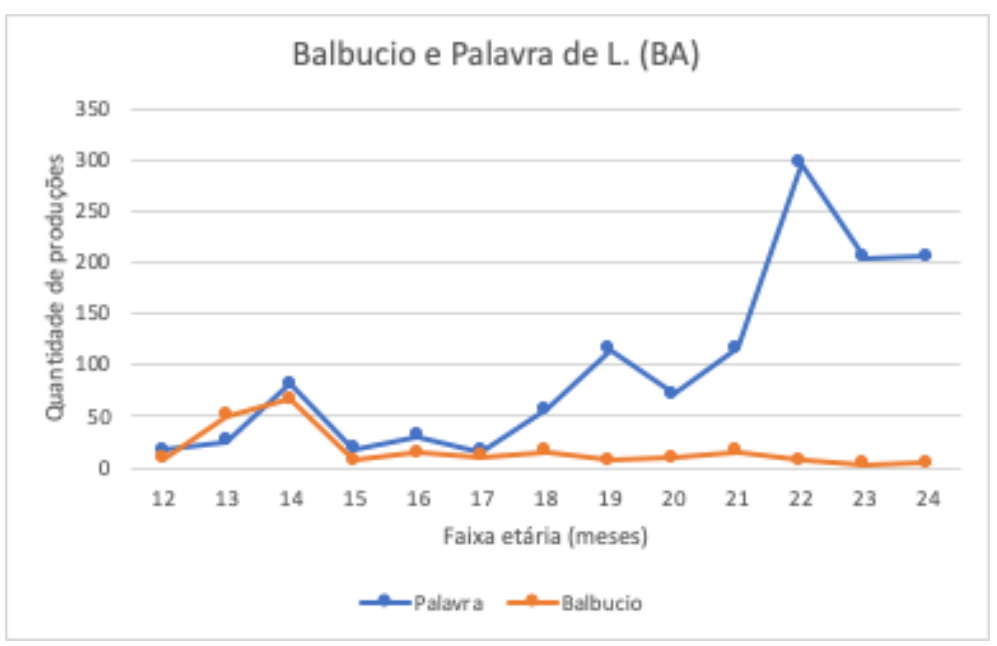

Fonte: autoria própria. 


\section{v. 10 (1)} 166-189 jan-abr 2020
Gráfico 5 - Distribuição de balbucio e palavra nas sessões de D. (BA)

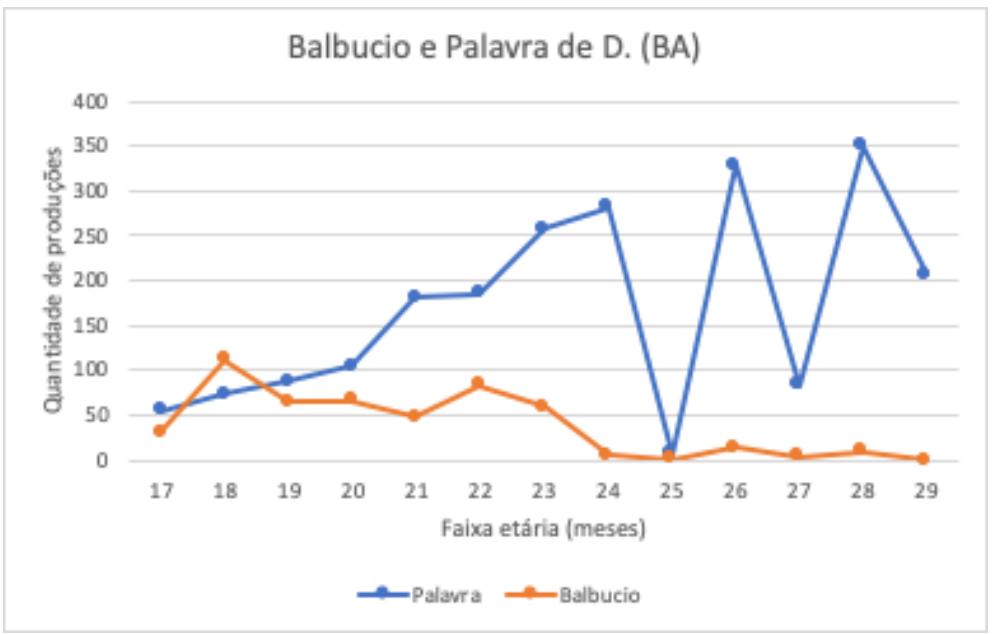

Fonte: autoria própria.

Gráfico 6 - Distribuição de balbucio e palavra nas sessões de $\mathrm{B}$. (BA)

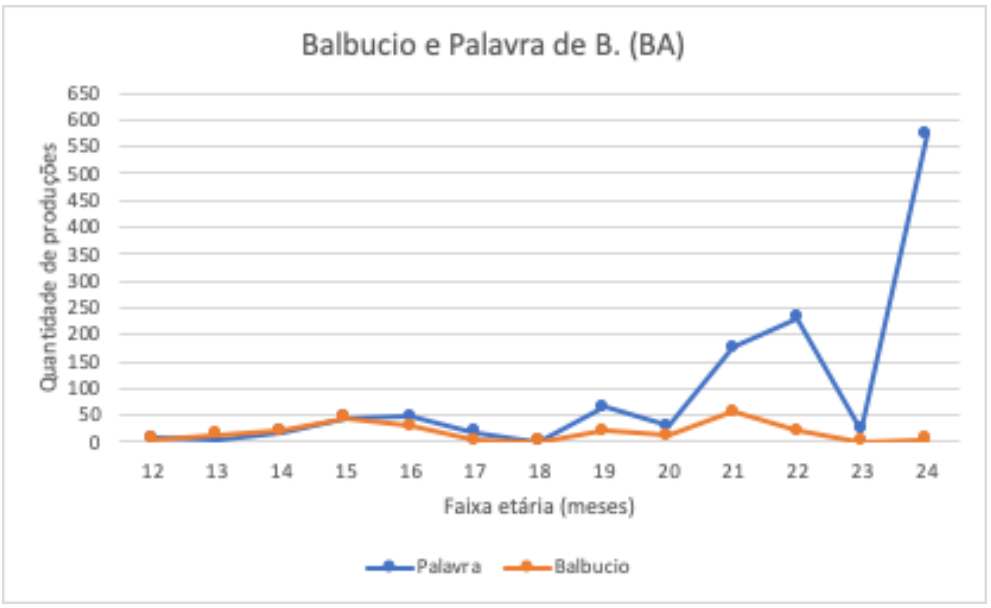

Fonte: autoria própria.

Gráfico 7 - Distribuição de balbucio e palavra nas sessões de $M$. (BA)

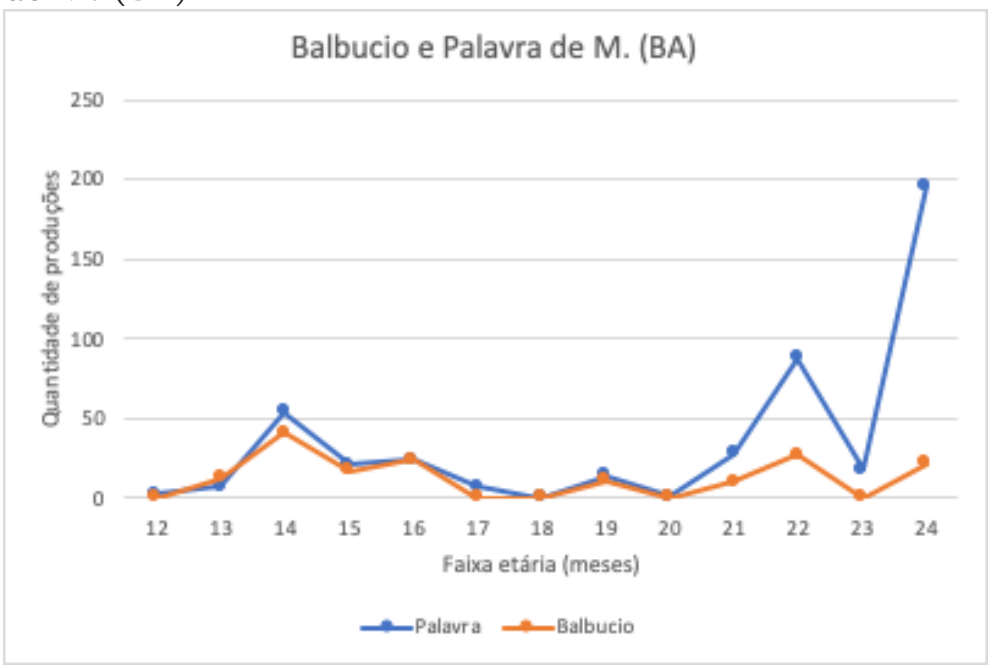

Fonte: autoria própria. 
Como os dados demonstram, o pareamento de forma e função nos dados - via dados de palavras - varia de acordo com as crianças. A tabela a seguir apresenta o mês a partir do qual houve predominância de produção de palavras nos dados de cada criança com as medidas de tendência central:

Tabela 2 - Mês a partir do qual teve predomínio de pareamento de forma e função nos dados.

\begin{tabular}{c|l}
\hline Criança/Sessão $\mathbf{F}+\mathbf{F}>$ balbucio & Medida de tendência central/resultado \\
\hline M. (SP) 14 meses & \multirow{3}{*}{ Média: 19 meses $(18,8)$} \\
\hline A. (SP) 19 meses & \\
\cline { 1 - 1 } G. (SP) 19 meses & \\
\cline { 1 - 1 } L. (BA) 18 meses & \\
\hline D. (BA) 20 meses & \\
\hline B. (BA) 21 meses & \\
\hline M. (BA) 21 meses & \\
\hline
\end{tabular}

Fonte: autoria própria.

Dessa maneira, considerando a variabilidade entre os dados de desenvolvimento das sete crianças, podemos afirmar que a faixa etária na qual há mais produções de palavras, ou seja, produções nos quais atestamos tanto função quanto conteúdo, é a dos 19 meses $(1 ; 7)$. Todavia, considerando as medidas de dispersão, o valor obtido para o desvio padrão foi o de $\sigma=2,4 /$ mês, o que nos faz ressaltar a necessidade de ser conduzida uma análise e tabulação atenta dos dados de desenvolvimento de cada criança. Interessantemente, as crianças gêmeas da Bahia, M. e G., apresentaram o mesmo mês como início do predomínio do pareamento de forma e função (21 meses/1;9), apesar da diferença na frequência dos dados produzidos.

No que se refere à presença de balbucio tardio, Elbers e Ton (1985) apresentam evidências, por meio da análise de dados de desenvolvimento fonológico do holandês, de que no período de transição balbucio e palavra são produzidos simultaneamente. Os dados das sete crianças categorizados como balbucio ou palavras, neste estudo, demonstram o mesmo em diferentes dialetos (São Paulo - capital/ Vitória da Conquista - interior da Bahia), como pode ser observado nos gráficos expostos anteriormente.

Além disso, dados mais tardios, como os de D. (BA) aos 2;5 (gráfico 5), mostram ainda produções que não puderam ser categorizadas 
V. 10 (1) 166-189 jan-abr 2020

como palavra de acordo com o método de Vihman e McCune (1994). Dessa maneira, candidatos que causam dúvida a respeito de ser palavra ou não podem estar presentes em dados mais tardios, o que torna necessário haver critérios sobre o que pode ser considerado palavra ou não mesmo que não seja focada a transição inicial entre o período do balbucio e o da palavra. Neste estudo, apresentamos o método que tem sido utilizado até então pelo nosso grupo de estudo. Além disso, desconhecemos outro método na literatura.

Por fim, em uma abordagem emergentista/funcionalista, não é possível analisar aspectos fônicos (forma) de desenvolvimento linguístico sem levar em consideração aspectos do significado (função). Entretanto, consideramos que, independente da visão, se inatista ou funcionalista, o pesquisador precisa estar amparado por um método ou pelo menos com critérios bem delineados sobre o que pode realmente ser considerado produção com forma e função linguística.

\section{Considerações finais}

Neste estudo, buscamos mostrar a vantagem de se utilizar o método de Vihman e e McCune (1994) para análise de dados de produção de crianças em fase de transição entre balbucio e palavras (ou enunciados de maneira mais geral) iniciais. De acordo com o método, pudemos observar que o pareamento de forma e função tende a iniciar a partir de 1 ano e 7 meses (19 meses).

Neste estudo, apresentamos e utilizamos o método de Vihman e McCune (1994) e uma revisão bibliográfica da literatura que está por trás da proposta dos autores. Tratamos neste estudo do pareamento da forma e do o conteúdo considerando dados de produção, o que precisa ser destacado por haver uma discrepância entre o que o bebê percebe e o que ele produz, podendo haver indício de intenção mesmo antes dela ser expressa via uma forma. Os estudos de percepção mostram que os bebês já têm acesso a informações prosódicas da sua língua materna mesmo antes de nascerem (MAMPE et al., 2009) e, depois do nascimento, a sua capacidade de perceber os sons da sua língua vai cada vez mais se aprimorando durante o primeiro ano de vida (WERKER; TEES, 1984). Já os de produção apontam para um desenvolvimento mais tardio, sendo iniciado, por volta dos 6 meses, com o balbucio (VIHMAN, 2014). De acordo com Kuhl et al. (2006, p.32), o balbucio e a estimulação auditiva fazem com que a criança consiga identificar o relacionamento entre os 
movimentos motores e os sons da fala, requeridos para a imitação vocal. Dessa forma, nesse período, há um pareamento do estímulo auditivo com a configuração vocal.

Quanto ao desenvolvimento da compreensão, Vihman (2014) aponta que, até os nove meses de idade, os bebês já conseguem se comunicar com as pessoas ao seu redor por meio do choro, grito, riso etc., conseguem reconhecer pessoas e objetos, compreendem o gesto de apontar, entre outros aspectos. Dessa maneira, o desafio aqui focado foi o de oferecer um instrumento para identificar produções que estejam mais próximas da configuração forma-função presente na língua alvo. Em um estudo futuro, pretendemos explorar o pareamento de forma e função em desenvolvimento inicial por meio de teste de percepção.

\section{Referências}

ALBANO, E. C. O gesto articulatório como unidade foiça abstrata: indícios da fala infantil e evidências da fala adulta. In: LAMPRECHT, R. (Org.). Aquisição da linguagem: questões e análises. Porto Alegre: EDIPUCRS, 1999.

BAIA, M. F. A. Os padrões emergentes no desenvolvimento fonológico. Projeto de pesquisa. Universidade Estadual do Sudoeste da Bahia, 2014.

BATES, E.; MACWHINNEY, B. Functionalism and the Competition Model. In: BATES, E.; MACWHINNEY, B. (Eds.). The Crosslinguistic Study of Sentence Processing. New York: Cambridge University Press, 1989.

BUDWIG, N. A. A Developmental-functionalist Approach to Child-language. New York: Routledge, 1995.

CHOMSKY, N. Lectures on Government and Binding: The Pisa Lectures. Cambridge: MIT Press, 1981.

CLARK, E. First language acquisition. New York: Cambridge University Press, 2003.

ELBERS, L.; TON, J. Play Pen Monologues: The Interplay of Words and Babbles in the First Words. Journal of Child Language, v. 12, p. 551- 565, 1985.

FERGUSON, C. A; FARWELL, C.B. Words and Sounds in Early Language Acquisition. Language, v. 51, p. 419-439, 1975.

FIKKERT, P.; LEVELT, C. C. How Does Place Fall Into Place? The Lexicon and Emergent Constraints in the Developing Phonological Grammar. In: AVERY, P.; DRESHER, E.; RICE, K. (Eds.)., Contrast in Phonology: Theory, Perception, Acquisition. Berlin: Mouton, 2008. p. 231-268.

GERKEN, L. Language Development. San Diego: Plural Publishing, 2008.

HALLIDAY, M. On the Transition from Child Tongue to Mother Tongue. In: WEBSTER, J. (Ed.). The Language of Early Childhood. London: Continuum, 2003 [1983]. p. 210-226. 
V. $10(1)$ $166-189$ jan-abr 2020

INGRAM, D.; INGRAM, K. D. A Whole-Word Approach to Phonological Analysis and Intervention. Language, Speech, and Hearing Services in Schools, v. 32, 271-283, 2001.

JUSCZYK, P. W.; BERTONCINI, J. Viewing the Development of Speech Perception as an Innately Guided Learning Process. Language and Speech, 31, p. 217238,1988

KENT, R. D. The Psychology of Speech Development: Co-emergence of Language and a Movement System. American Journal of Psychology, 246, p. 888-894, 1984

KUHL, P. et al. Novas teorias de aprendizagem. In: KUHL, P. et al. Língua, cultura, mente, cérebro: progresso nas fronteiras entre disciplinas. São Paulo: Paulistana, 2006.

LINDBLOM, B. Phonological units as adaptive emergent of lexical development. In: FERGUSON, A.; MENN, L.; STOEL-GAMMON, C. Phonological Development Models, Research, Interpretations. Timonium, MD: York Press, 1992.

LOCKE, J. L. The Child's Path to Spoken Language. Cambridge: Havard University Press, 1993.

MACKEN, M. Developmental Reorganization of Phonology: A Hierarchy of Basic Units of Acquisition. Lingua, v. 49, p. 11-49, 1979.

MAMPE, B. et al. Newborns' Cry Melody Is Shaped by Their Native Language. Current Biology, v. 19, p. 1994-1997, 2009.

SANTOS, R. S. A aquisição do ritmo em português brasileiro. Projeto USP, 2005.

THELEN, E. Rhythmical Behavior in Infancy: An Ethological Perspective. Developmental Psychology, v. 17, 237-57, 1981.

THELEN, E.; SMITH, L. B. Dynamic Systems Approach to the Development of Cognition and Action. Cambridge, MA: MIT Press, 1994.

VIHMAN, M. M.; MCCUNE, L. When is a Word a Word? Journal of child Language, v. 21, p. 517-542, 1994.

VIHMAN, M. M. Phonological Development: The Origins of Language in the Child. Cambrigde: Blackwell Publishers, 1996.

VIHMAN, M. M.; VELLEMAN, S. L. Whole-Word Phonology and Templates: Trap, Bootstrap, or Some of Each? Language, Speech, and Hearing Services in Schools, v. 33, p. 9-23, 2002.

VIHMAN, M.; CROFT, W. Phonological Development Toward a "Radical" Templatic Phonology. Linguistics, v. 45, n. 4, p. 683-725, 2007.

VIHMAN, M. M. Precursors of Language: From 18 Months of Life. Phonological Development: The First Two Years. Oxford: Wiley Blackwell, 2014. 
WATERSON, N. Child Phonology: A Prosodic View. Journal of Linguistics, V. 7, p. 179-211, 1971.

WERKER, J. F.; TEES, R. C. Cross-language Speech Perception: Evidence for Perception Reorganization During the First Year of Life. Infant Behaviour and Development, v. 7, p. 49-63, 1984. 